their perches and flattening the odd ant.

The technical achievement in producing this film can only be applauded. Planning and design took two years, filming another three, during which time the team developed its 'macrocinematic' techniques, with special cameras, radio-controlled camera mounts, lighting set-ups that did not bake the cast and, perhaps most difficult of all, suitable conditions to keep the insects happy and performing despite being only an antenna-length from the lens.

The soundtrack is superb. Music by Bruno Coulais is merged with sounds collected on location. The creatures' clattering footsteps, chirping and buzzing are truly impressive at this scale. Bee-flies sound like a motor racing team, and a millipede drifts along like a steam train.

The words of the final song - "open your eyes before you die" to this "world beyond imagination yet beneath our notice" (sung by an angelic choirboy) makes one wish that even the small amount of commentary had not been translated from the French. But one has to admire the skill and beauty of the film. And when things threaten to get just a little too romantic, something else (and I almost said someone else) gets eaten.

Helen Phillips is on the editorial staff of Nature.

\section{New journals}

This year, Nature's annual new journals review supplement will appear in the issue of 11 September. Publishers and learned societies are invited to submit journals for review, as well as details of any eligible electronic journals, taking note of the following criteria:

- Journals that first appeared during or after June 1995 and issued at least four separate numbers by the end of May 1997 will be considered.

- Journals covering any aspect of science are eligible, although those dealing with clinical medicine and pure mathematics are excluded, as are publications of abstracts

- Frequency of publication must be at least three times a year. The main language used must be English. Translation journals in English are, of course, eligible.

- Deadline for submission is 6 June. When submitting journals for review, please send at least four different issues (the first, the most recent and any two others) of each title, together with full details of subscription rates.

For further information please contact Peter Tallack, Book Reviews Editor, Nature, Macmillan Magazines, Porters South, Crinan Street, London N1 9XW, UK.

Tel: +44 (0)171 8434567.

e-mail: p.tallack@nature.com

\title{
In retrospect chosen by David Hughes
}

\section{Frontiers of Astronomy}

by Fred Hoyle

(1955)

Most of today's astronomers experienced, when young, a 'road to Damascus' conversion that seduced them from the school-taught subjects such as physics and mathematics, and diverted their paths towards astronomy. Hoyle has been responsible for many of these conversions, and his Frontiers of Astronomy was often the "holy book. Here Hoyle is happy to divide scientists into two groups, these being astronomers and the rest, and he makes absolutely no bones about telling the world which category he thinks is the superior.

Hoyle stresses the fact that the joy of being an astronomer is that in many ways you are helpless. The Universe cannot be touched. Whereas other scientists do experiments, astronomers merely observe. Astronomers cannot go on 'field trips' and wander off around the Galaxy investigating objects of interest. An astronomer cannot tear to pieces objects such as planets and stars, using techniques much loved by physicists. Even though astronomers can build big telescopes and efficient detectors, in essence they are meek. They cannot alter the radiation that comes into the telescope, or experiment with its source. They have to sit here on Earth and simply accept what comes down the tube.

But they do have one overwhelming advantage, and that is variety. The Universe is so vast, and the expanses of time that are of astronomical interest are so great, that almost every conceivable type of astronomical process is still taking place somewhere. In many astronomical fields there is an embarrassingly huge flood of information. In others the astronomers are convinced that if only they could look a little further, or probe back in time slightly more, or slightly increase the resolution of their images and spectra, the picture would become clear. And it requires the straitjacket of astronomical theory not only to untangle and decipher the information flood but also to encourage the desired instrumental advances.

Hoyle also divides astronomers into two types. On the one hand there are those who concentrate solely on the known. They give the impression that the job of cataloguing, exploring and understanding the Universe is nearly complete. But Hoyle will have nothing to do with this complacency. Hoyle's astronomers are pioneers; they are the vanguard troops in the scientific campaign against the unknown.

This book concentrates on the oddities and mysteries. And they are not just the astronomical mysteries that, by chance, occupied the mind of a Cambridge lecturer in mathematics, in his late thirties, writing in 1954, three years before the dawn of the space age. It is amazing just how many of Hoyle's mysteries are still unsolved today. The range can be judged by the questions he

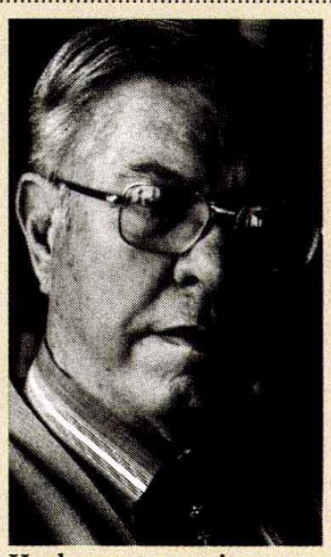

poses. Close to home, he worries about why earthquakes do not occur at depths below 700 $\mathrm{km}$ and what the temperature of the Atlantic Ocean was 200 million years ago. He then ponders why the Sun spins so slowly and how magnetism affects Hoyle: mystery writer the Sun's atmosphere. Then come the evolution of stars and the unravelling of the way in which stellar compositions changed with time. This is followed by the mysteries concerning the methods of galaxy and galactic arm formation and the distribution of galaxies in space. And the book ends with the perennial teaser: why did the Universe form in the first place?

What is also so 'classic' about this book is its style. Hoyle does not introduce any mathematical equations. He simply writes for the interested citizen with a clarity that is honed by the discipline of university lecturing and $\mathrm{BBC}$ radio broadcasting.

Throughout the text Hoyle is mindful of that unwritten convention that irritated his Cambridge colleague Ray Lyttleton: apparently it was then (and still is) bad form for an observational astronomer to be challenged on grounds of competence, whereas theoreticians were routinely challenged in ways that implied incompetence almost to the point of imbecility. All I can say is that, on the evidence of Frontiers of Astronomy, Hoyle must have been challenged less than most. This book still encompasses all the joys and excitement of the astronomer's exploration of the scientific frontiers. Astronomy should be all about struggling with the great questions. It is like a good detective story - there is some vital clue that should reveal the solution to the mystery, but the clue and its significance are far from obvious.

Hoyle is an astronomer's astronomer. To quote from the first chapter of Frontiers of Astronomy: "Man's claim to have progressed far beyond his fellow animals must be supported not by his search for food, warmth and shelter (however ingeniously conducted), but by his penetration into the very fabric of the Universe. It is in the world of ideas and in the relation of his brain to the Universe itself, that the superiority of Man lies. The rise of Man may justly be described as an adventure in ideas."

Read this book and prepare to join the endeavour.

David Hughes is in the Department of Physics, University of Sheffield, Sheffield S3 7RH, UK. 